\title{
NOVES TENDÈNCIES EN LA RECERCA, LA TRANSFERÈNCIA I LA DIDÀCTICA DELS ESTUDIS CLÀSSICS
}

\author{
PILAR GÓMEZ CARDÓ \\ Universitat de Barcelona \\ pgomez@ub.edu \\ ORCID: 0000-0001-6560-2836 \\ VÍCTOR SABATÉ VIDAL \\ Universitat de Barcelona \\ vsabatev@gmail.com \\ ORCID: 0000-0003-1699-8111 \\ JAVIER VELAZA FRÍAS \\ Universitat de Barcelona \\ velaza@ub.edu \\ ORCID: 0000-0002-5811-3345
}

Els dies 2, 3 i 4 d'abril de 1968, les mil·lenàries parets del monestir de Santa Maria de Ripoll acolliren el I Simposi de la Secció de Barcelona -l'actual Secció Catalana- de la Sociedad Española de Estudios Clásicos, impulsat pel Dr. Josep Alsina Clota. ${ }^{1}$ Aquest esdeveniment, que es recorda sovint com una fita en la història dels estudis clàssics a casa nostra, donà el tret de sortida a una sèrie de trobades que han esdevingut un emblema de les activitats dutes a terme per la Secció Catalana, fins i tot més enllà dels límits del Principat, atès que en tots els simposis hi ha hagut una destacada participació de filòlegs de fora de Catalunya. ${ }^{2}$ Cinquanta anys després d'aquell primer congrés, els dies 18, 19 i 20 d'octubre de 2018 tingué lloc a la Facultat de Filologia de la Universitat de Barcelona el XVIII Simposi d'Estudis Clàssics: fou el tercer celebrat a la ciutat comtal, després del sisè (1981), en què es commemorà el bimil-lenari de la mort de Virgili (19 aC), i del dissetè (2013), que dugué per títol Omnia mutantur.

El XVIII Simposi se centrà monogràficament en les noves tendències en els estudis clàssics. Les sessions tingueren com a eix vertebrador els tres temes següents, cadascun dels quals introduït per una ponència plenària:

1. Noves eines i nous mètodes de recerca, $a m b$ “ ¿Conocemos de verdad la lengua griega? Últimos avances en semántica y sintaxis del griego antiguo", a

\footnotetext{
${ }^{1}$ Les actes del simposi es publicaren als volums 2.2 (1968) i 3.1 (1969) del Boletín del Instituto de Estudios Helénicos, fundat i dirigit pel mateix Dr. Alsina.

2 Per a una panoràmica dels primers setze simposis, vegeu González Senmartí 2010, amb un apèndix de les actes publicades, bona part de les quals es pot descarregar al web de la Secció Catalana: <http://seec.cat/publicacions> [consulta: 17 juliol 2020]. Les del XVII Simposi veieren la llum el 2016 en dos volums: Borrell i Gómez Cardó 2016; Borrell i de la Cruz 2016.
} 
càrrec de Jesús de la Villa Polo (Universidad Autónoma de Madrid), president de la Sociedad Española de Estudios Clásicos.

2. Experiències innovadores en la transferència dels estudis clàssics, amb "Transferencia de conocimientos en los estudios clásicos: presente y futuro de la epigrafía digital", a càrrec de Manuel Ramírez Sánchez (Universidad de Las Palmas de Gran Canaria).

3. Noves tendències didàctiques en l'ensenyament del grec, del llatí i de la cultura clàssica, amb "Volver a la tradición: Latine discere iuvat", a càrrec d'Antonio G. Amador (IES Severo Ochoa, Granada).

En aquest volum monogràfic de la revista Anuari de Filologia: Antiqua et Mediaeualia, intitulat precisament Noves tendències en els estudis clàssics, el lector hi trobarà una selecció dels treballs que s'hi presentaren, reelaborats i sotmesos a un procés de revisió per parells cecs que n'assegura la qualitat i el rigor científics. Les comunicacions adoptaren formes ben diverses i constituïren una mostra de la riquesa i la vitalitat de les nostres disciplines, amb un èmfasi especial en les humanitats digitals i en la interdisciplinarietat. Esperem que $l^{\prime}$ ambient $d^{\prime}$ intercanvi de recerques, idees i experiències que es respirà durant aquelles jornades pugui copsar-se també en aquestes pàgines.

El volum va dedicat a la memòria del nostre malaurat company, el Dr. Lambert Ferreres, catedràtic de Filologia Llatina i membre del Departament de Filologia Clàssica, Romànica i Semítica de la Universitat de Barcelona. El professor Ferreres ens va deixar fa tot just uns mesos, el primer d'abril de 2020, víctima d'aquesta pandèmia que ha canviat radicalment les nostres vides i que, com a signe de major crueltat, ens impedeix d'acomiadar-nos dels qui se' $n$ van i de retre'ls l'homenatge públic que es mereixen. A banda de la seva dedicació a la Filologia Llatina, Lambert Ferreres fou soci d'ençà de la seva època d'estudiant i membre actiu de la Secció Catalana de la SEEC: formà part de diverses juntes directives $\mathrm{i}$, entre moltes altres tasques, edità les actes del IX Simposi d'Estudis Clàssics, en honor del seu mestre Virgilio Bejarano (Ferreres 1991), i el segon volum del XVI Simposi, Artes ad humanitatem (Borrell i Ferreres 2010). Però, més enllà de la seva implicació en la Secció Catalana i per sobre de tot, trobarem a faltar la seva gran bonhomia, el seu tracte sempre respectuós, el seu saber fer, i la seva agudesa, rigor i pulcritud filològiques.

Barcelona, 20 de juliol de 2020

BIBLIOGRAFIA

Borrell, E. i DE LA CRUZ, Ó. (eds.) (2016), OMNIA MVTANTVR. Canvi, transformació i pervivència en la cultura clàssica, en les seves llengües $i$ en el seu llegat, vol. II, Barcelona, Secció Catalana de la SEEC / Universitat de Barcelona. 
BORRELl, E. i FERRERES, L. (eds.) (2010), Artes ad humanitatem, vol. II: Literatura, lingüística, filologia $i$ tradició clàssica a l'entorn del món romà, Barcelona, Secció Catalana de la SEEC.

BORRell, E. i GÓMEZ CARDÓ, P. (eds.) (2016), OMNIA MVTANTVR. Canvi, transformació i pervivència en la cultura clàssica, en les seves llengües $i$ en el seu llegat, vol. I, Barcelona, Secció Catalana de la SEEC / Universitat de Barcelona.

FERRERES, L. (ed.) (1991), Actes del IXè Simposi de la Secció Catalana de la SEEC (St. Feliu de Guíxols, 13-16 d'abril de 1988). Treballs en honor de Virgilio Bejarano, 2 vols., Barcelona, Universitat de Barcelona / Secció Catalana de la SEEC.

GONZÁlez SENMARTí, A. (2010), “Els estudis clàssics a Catalunya i els simposis de la Secció Catalana de la SEEC", dins Artes ad humanitatem, vol. I: Mitologia, pensament, literatura, lingüística, filologia i tradició clàssica a l'entorn del món grec, Borrell, E. i Gómez Cardó, P. (eds.), Barcelona, Secció Catalana de la SEEC, 373386. 